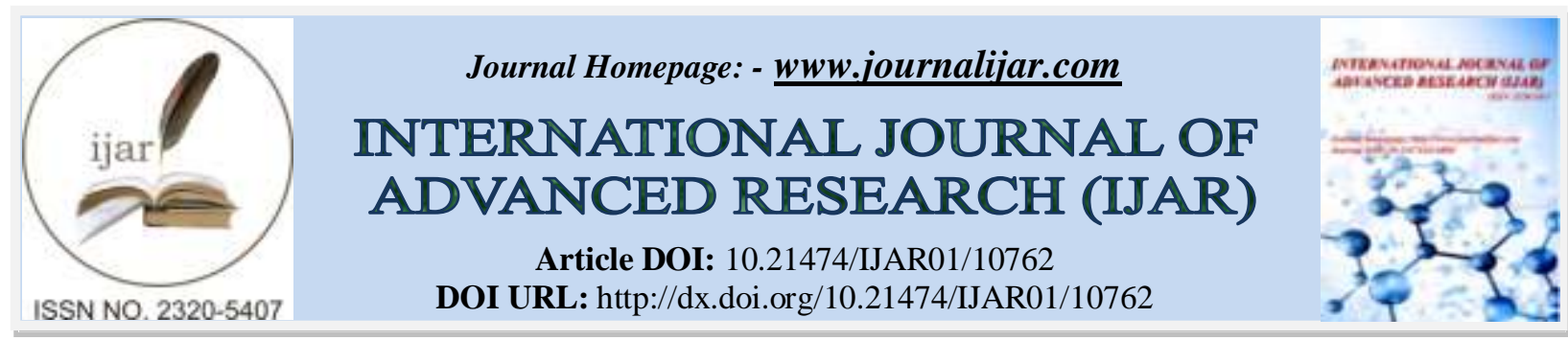

RESEARCH ARTICLE

\title{
EVALUATION OF MASTECTOMY FLAPS FIXATION VERSUS CONVENTIONAL METHOD IN REDUCTION OF SEROMA AFTER MODIFIED RADICAL MASTECTOMY
}

Hany Mohamed, Sherif Holyl and Hatem Mohammed

General Surgery Departments, Faculty of Medicine, Zagazig University.

\section{Manuscript Info}

Manuscript History

Received: 25 December 2017

Final Accepted: 27 January 2018

Published: February 2018

Key words:-

Seroma, Flap Fixation, Modified Radical Mastectomy

\begin{abstract}
Background: Post-operative seroma is a common complication that occurs after modified radical mastectomy, due to accumulation of fluid in the dead space between skin flaps and the underlying chest wall and axilla. The aim of this study is to evaluate the effect of fixation of flaps by suturing to the chest wall muscle on the seroma formation.

Patients and Methods: Our prospective study was done in general surgery department, Zagazig University, from Jan 2016 to Nov. 2017. Included 70 female patients with breast cancer operated by modified radical mastectomy, the patients were classified in to two groups $(\mathrm{A}, \mathrm{B})$ each group 35 female patients( $\mathrm{N}=35)$. Group (A) operated by quilting flap fixation technique while group (B) operated by conventional method. The patients were followed up for one month and both preoperative and postoperative data are recorded, reviewed and statistically analysed for comparison between the two groups.

Results: The preoperative results shows nearly similar results between the two groups regarding the age and body mass index. The breast laterality, the comorbidity (diabetes mellitus (DM), hypertension (HTN), anticoagulant drugs) and stages (T,N) shows small difference between the two groups. the post-operative results shows no significant difference in the operative time, number of Infected seroma, Haematoma and Infected wound $(\mathrm{P}>0.05)$. Total amount of drained fluid $(\mathrm{ml})$, the duration of drainage (day), Seroma post drain removal and number of seroma needed aspiration all shows significant difference between the two groups $(\mathrm{P}<0.05)$.

Conclusion: Reduction of the dead space during modified mastectomy by suturing and fixation of the skin flaps to the chest wall is a good technique to decrease post-operative seroma.
\end{abstract}

\section{Introduction:-}

Breast cancer is considered the second cause of cancer death in women all over the world in the last three decades. ${ }^{1}$ Seroma formation is a prevalent complication of breast surgeries, with incidence $3 \%$ to $85 \%^{2}$, while pathophysiology of seroma is vague, many factors produce fluid collection after mastectomy ${ }^{3}$, as extensive dissection will lead to large dead space under the flaps, chest wall Irregularity as in deep axillary fossa makes difficulty in flap adherence, chest wall movement during breathing and shoulder movement produce a shearing force which retard adherence of the flaps. ${ }^{4}$ Seroma occur secondary to interruption of lymphatic channels which 
unavoidably complicates excessive dissection and interruption of tissue planes producing a dead space. Accumulation of seroma fluid expands the skin leading to discomfort, reduction of ipsilateral shoulder movement and increase incidence of the infection. Traditional wound closure using suction drain post mastectomy to prevent seroma although it commonly occurs after removal of the drain ${ }^{5}$, Excessive Electerocautery use was found to increase formation of seroma after mastectomy. ${ }^{6}$ The hypothesis of suturing efficacy that the dead space is a major factor for seroma formation, and the surgical technique used to obliterate this dead space may decrease the incidence of seroma. ${ }^{7}$ So, ideal wound closure must reduce lymph spillage and serum leak, provide good holding of skin flaps to the chest wall, eliminate dead space, and permit rapid eradication of collected fluid. For this, there are many techniques for flap fixation and wound drainage, decreasing postoperative shoulder movement and using adhesive glue to promote wound healing and prevent seroma formation. ${ }^{8}$ the aim of this study is to evaluate the results of post modified radical mastectomy skin flap fixation regarding operative time, seroma formation, subcutaneous drainage amount and duration and surgical site infection rates.

\section{Patient and Method:-}

This study is prospective comparative clinical trial, conducted in general surgery department, Zagazig University, in the period between January 2016 and November 2017, on 70 female patients undergoing modified radical mastectomy for breast cancer treatment.

Patients were randomly allocated using computer generated randomization cards into two groups; group A 35 patients, underwent post mastectomy skin flap fixation, and group B 35 patients underwent wound closure without skin flap fixation.

All patients signed an informed written consent before participation in the study, the study was approved by the research ethical committee of our hospital.

The study had no external funding and the authors had no conflict of interest .In this study we included patients with operable breast cancer stage (I, II), non-recurrent cases with no previous breast surgery (except for biopsy of the current disease).

All patients of the study were diagnosed by thorough history taking included comorbidity (DM,HTN, Anticoagulants), full clinical examination; they underwent breast ultrasonography and /or mammography, biopsy (fine needle aspiration cytology (FNAC), core needle biopsy or excisional biopsy) with histopathological examination for confirmation of diagnosis. Chest X ray, C.T chest, abdominal ultrasound or C.T abdomen or PET scan for exclusion of metastasis. Routine preoperative workup including laboratory tests, cardiac, medical and anaesthiologist consultation,

\section{Surgical Procedures:}

Preoperative $1 \mathrm{gm}$. I.V. ceftriaxone was given to all patients prior to skin incision. The patients were operated under general anaesthesia with endo-tracheal tube, supine position, transverse elliptical incision $(4-5 \mathrm{~cm})$ around the lesion, elevation of the breast flaps to the upper and lower limits of the breast, excision of the breast with the pectoralis fascia and clearance of the axilla with preservation the long thoracic nerve and nerve to latismus dorsi using diathermy for haemostasis during the operation. During closure; in the quilting group (A) we used absorbable suture (vicryl 2/0) to take rows of multiple suture at $3 \mathrm{~cm}$ distance between the subcutaneous tissues and the under lying muscle at the site of removed breast and axilla and also at the flap edges then closure of the skin over subcutaneous suction drain size $18 \mathrm{~F}$. In conventional group (B) the skin flaps were closed in classic method over subcutaneous suction drain has the same size. Patients were discharged after 1 to 3 days with drains which removed when the amount of drained fluid become $<30$ milliliter $(\mathrm{ml}) /$ day during follow up in outpatient's clinics. Patients were followed up for one month by the attending surgeons. Preoperative data, patient's characteristics, operative and follow up data including amount of drainage, drainage time, seroma incidence, wound infection rate, were well presented and statistically analysed using SPSS program package version 22, Z test was used for comparison between percentages of categorical data paired t test, means and standard deviation was used for comparison between continuous data, $\mathrm{p}$ value was considered significant at values less than 0.05 at confidence interval $95 \%$. 


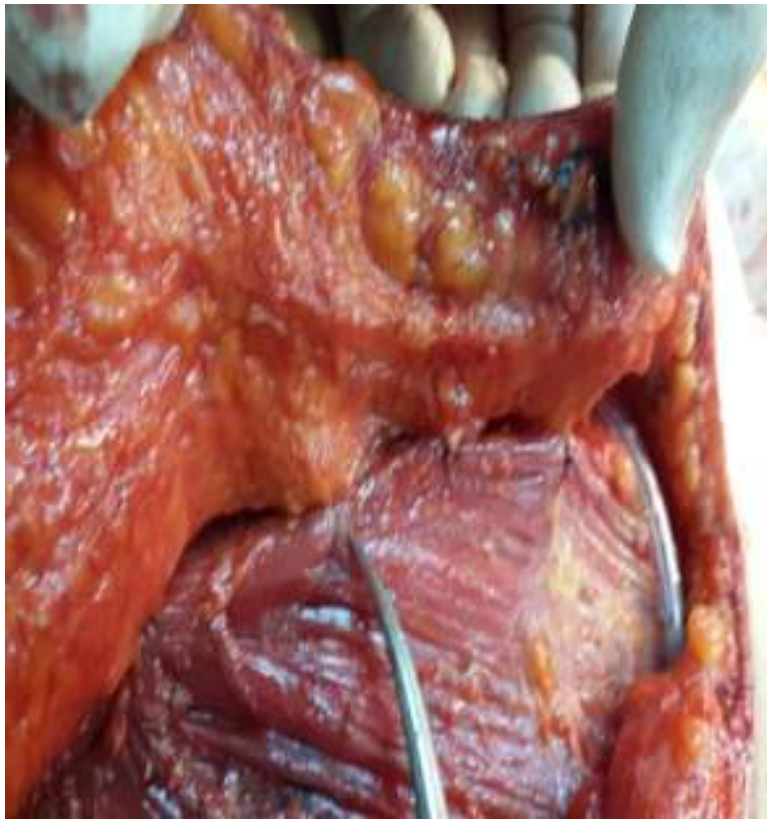

Figure(1):Suturing of the breast flap To the pectoralis major muscle.

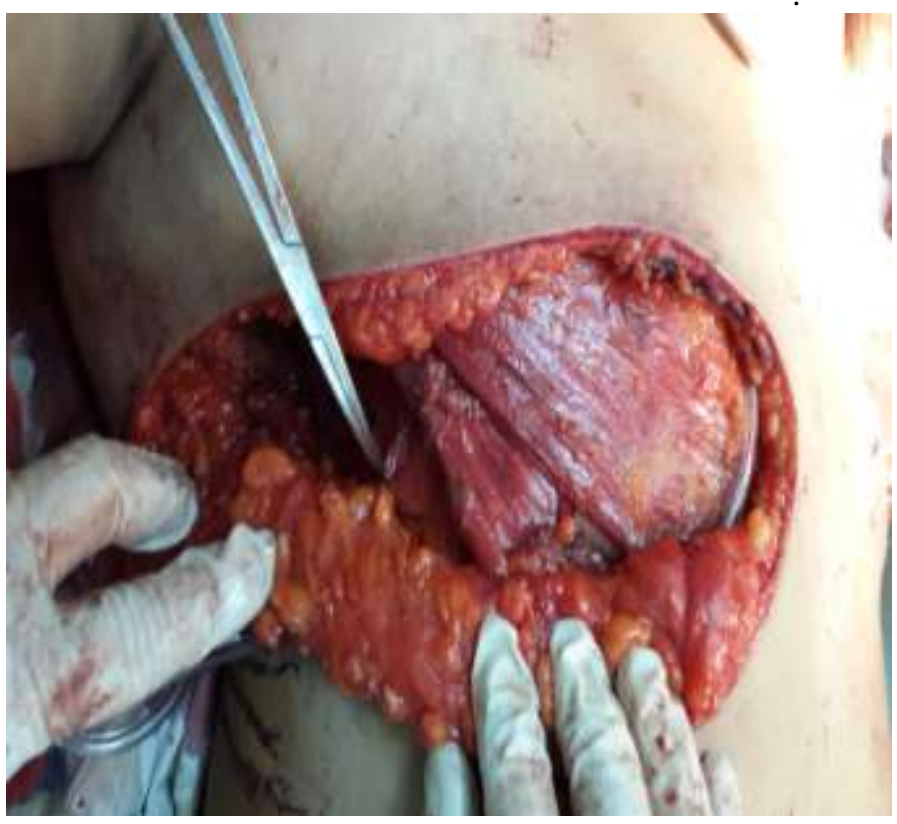

Figure(2):Suturing of the breast flap To the serratus anterior in the axilla.

\section{Results:}

As presented in table 1; preoperative data show age of group A patients ranged between 31 and 65 with mean \pm SD (49.6 \pm 8.42$)$, while in group B it ranged between 32and 69 with mean $\pm \operatorname{SD}(48.9 \pm 10.3)$, with nearly similar results between the two groups. According to the Body mass index of group A the Mean \pm SD (29.2 \pm 1.29$)$, Range (2632.7) and in the group B the Mean \pm SD (29.1 \pm 2.39$)$, Range (24-33.3) also with small difference between the two groups. We detected no significant differences regarding laterality and stage of the disease, associated comorbidities or body mass index between both groups.

Table (1):- Shows the preoperative data.

\begin{tabular}{|l|l|l|}
\hline characters & $\mathrm{A}(\mathrm{N}=35)$ & $\mathrm{B}(\mathrm{N}=35)$ \\
\hline Age in each group & & \\
Mean \pm SD & $49.6 \pm 8.42$ & $48.9 \pm 10.3$ \\
Median (Range) & $50(31-65)$ & $49(32-69)$ \\
\hline Body mass index (BMI) & & \\
Mean \pm SD & $29.2 \pm 1.29$ & $29.1 \pm 2.39$ \\
Median (Range) & $29.4(26-32.7)$ & $29.1(24-33.3)$ \\
\hline Right side cancer & $17(48.5 \%)$ & $16(45.7 \%)$ \\
\hline Left side cancer & $18(51.4)$ & $19(54.3 \%)$ \\
\hline Diabetes mellitus & $5(14.3 \%)$ & $6(17.1 \%)$ \\
\hline Hypertension & $6(17.1 \%)$ & $8(22.9 \%)$ \\
\hline Anticoagulants & $1(2.9 \%)$ & $2(5.7 \%)$ \\
\hline Tumour size(T- stage) & & \\
T1 $(<2$ cm) & $8(22.9 \%)$ & $9(25.7 \%)$ \\
T2 $(2-5 \mathrm{~cm})$ & $18(51.4 \%)$ & $19(54.3 \%)$ \\
T3 $(>5 \mathrm{~cm})$ & $9(25.7 \%)$ & $7(20 \%)$ \\
Lymph nodes(N. stage) & & \\
N1 & $22(62.9 \%)$ & $24(68.6 \%)$ \\
N2 & $13(37.1 \%)$ & $11(31.4 \%)$ \\
\hline
\end{tabular}


The post-operative findings as shown in table 2 , we found that, the operative time in the group (A) ranged between 90 and 155 minutes, the Mean \pm SD $(126.86 \pm 20.1)$ while in the group (B) it ranged between 80 and 145 minutes, the Mean \pm SD $(120.29 \pm 18.59$ with non-significant difference $(\mathrm{P}=0.079)$. Total amount of drained fluid (ml) in the group A ,The Mean \pm SD1012.3 \pm 372.21 , Range (300-1950) while in group (B), Mean $\pm \operatorname{SD}(2055.57 \pm 727.32)$, Range (425-3200) with significant difference $(\mathrm{P}<0.0001)$.

Regarding the duration of drainage (day), in the group (A) The Mean \pm SD (10.29 \pm 1.96 , range (7-13) with significant difference $(\mathrm{P}<0.0001)$. Both seroma post drain removal and number of seroma needed aspiration shows significant difference between the two group $(\mathrm{P}<0.05)$. While the number of infected seroma, Haematoma and Infected wound shows non-significant difference between the two groups $(\mathrm{P}>0.05)$.

Table (2):- Operative and follow up data.

\begin{tabular}{|c|c|c|c|}
\hline Characters & A & B & $\mathrm{P}$ value \\
\hline $\begin{array}{l}\text { Operative time (min) } \\
\text { Mean } \pm \text { SD } \\
\text { Median (Range) }\end{array}$ & $\begin{array}{l}126.86 \pm 20.1 \\
130(90-155)\end{array}$ & $\begin{array}{l}120.29 \pm 18.59 \\
125(80-145)\end{array}$ & $\mathrm{P}=0.079$ \\
\hline $\begin{array}{l}\text { Total amount of drained fluid }(\mathrm{ml}) \\
\text { Mean } \pm \text { SD } \\
\text { Median (Range) }\end{array}$ & $\begin{array}{l}1012.3 \pm 372.21 \\
970(300-1950)\end{array}$ & $\begin{array}{l}2055.57 \pm 727.32 \\
2200(425-3200)\end{array}$ & $\mathrm{P}<0.0001$ \\
\hline $\begin{array}{l}\text { Duration of drainage (day) } \\
\text { Mean } \pm \text { SD } \\
\text { Median (Range) }\end{array}$ & $\begin{array}{l}10.29 \pm 1.96 \\
11(7-13)\end{array}$ & $\begin{array}{l}13 \pm 2.38 \\
13(9-19)\end{array}$ & $\mathrm{P}<0.0001$ \\
\hline Seroma post drain removal & $2(5.7 \%)$ & $8(22.9 \%)$ & $\mathrm{P}<0.05$ \\
\hline Number of seroma needed aspiration & $1(2.9)$ & $6(17.1 \%)$ & $\mathrm{P}<0.05$ \\
\hline Infected seroma & 0 & $2(5.7 \%)$ & $\mathrm{P}>0.05$ \\
\hline Haematoma & $2(5.7 \%)$ & $8(22.9 \%)$ & $\mathrm{P}>0.05$ \\
\hline Infected wound & $1(2.9 \%)$ & $2(5.7 \%)$ & $\mathrm{P}>0.05$ \\
\hline
\end{tabular}

\section{Discussion:-}

Seroma and its related side effects remain the most postoperative problem following breast surgery, proving that wound drainage is insufficient in prevention of seroma ${ }^{9,10}$. The amount of dissection is the most effective factor in accumulation of the seroma, So it is vital to obliterate the dead space during breast surgery .Many techniques were used to abolish the dead space to decrease formation of seroma. Halsted initially advised making a short upper flap and fixing it by interrupted silk suture to the fascia below the first rib with skin graft for the remaining defect ${ }^{11}$. Pressure dressing or compression bandages are not successful in prevention of seroma; Therefore, quilting of the skin flaps or fixation appears to be more effective ${ }^{12,13}$. The key to decrease collection of seroma seems to include the dead space obliteration. Although, the techniques used to obtain this target have many debate and controversies ${ }^{14}$. This study aim to assess the effect of quilting breast flaps in prevention of seroma formation .The operative and postoperative results shows that there is no significant difference in the operative time between the two groups $(\mathrm{P}=$ 0.079).This agree with the studies that shows that the dead space obliteration did not increase the operative time or postoperative complications, indicating its safety besides minimizing the rate of seroma formation ${ }^{15,16}$. In our study the total amount of drained fluid (ml) shows significant difference between the quilting group A and the conventional group B ( $\mathrm{P}<0.0001)$.this is similar to the result documented by Sakkary with decrease in the mean from $2017.8 \mathrm{~mL}$ in the control group to $524.8 \mathrm{ml}$ in the intervention group $(P<0.001){ }^{17}$.also there is significant decrease in the mean duration of drained fluid (day) from13 day in group B to 10.29 day in group A ( $<<0.0001)$ .This agree with the significant results reported by Sakkary (from 13.4 to $5, P<0.001$ ). according to seroma formation it occur in 2 cases $(5.7 \%)$ in group A while occur in 8 cases $(22.9 \%)$ with significant difference between the two results $(\mathrm{P}<0.05)$. This decreases in incidence of seroma is similar in the range with many preceding studies ${ }^{18}$. 
our study shows that dead space obliteration minimize the seroma formation which proven by multiple variates analysis, this coincide with Anjani et al. study which prove that suturing and fixation of the breast flaps to the underlying muscles significantly and dramatically lead to prevention of seroma formation due to reduction of the dead space below the breast flaps ${ }^{19}$.Also, the result of obliteration of the dead space in prevention of seroma was approved by met-analysis of van Bemmel et al. ${ }^{20}$. furthermore Faisal et al., stated a significant decrease in the whole amount of the seroma after axillary exclusion ${ }^{21}$. According to the number of seroma needed aspiration depending on clinical examination, there is significant difference between the two group $(\mathrm{P}<0.05)$. Seroma increase the duration of hospital stay, increase the Infection rate and delayed the adjuvant therapy ${ }^{22}$. So, the cost is higher in the medical care of the group of cases suffering from the seroma and its side effects ${ }^{23}$. In our study Although the number of diabetic patients is nearly similar in the two groups, the number of seroma is more in the group B .this agree with past studies that conclude that DM is associated with postoperative seroma and obliteration of the dead space reduce the seroma formation ${ }^{24}$. In our study there is small number of infected seroma and infected wound in both group with insignificant difference $(\mathrm{P}>0.05)$.this may be due preoperative prophylactic antibiotics and good sterilization. This agree with the rates of surgical site infection reported in the literature after modified radical mastectomy ${ }^{25}$.

\section{Conclusion:-}

Reduction of the dead space during modified radical mastectomy by suturing and fixation of the skin flaps to the chest wall is a simple and good technique that significantly reduce the post-operative seroma, duration of drainage. According to our study we recommended it to be a routin step in the modified radical mastectomy

\section{References:-}

1. Jemal A, Siegel R, Ward E, Hao Y, Xu J, Murray T, et al. Cancer statistics, 2008. CA Cancer J Clin 2008;58:71-96.

2. Kumar S et al. Post-mastectomy seroma: a new look into the aetiology of an old problem. J R Coll Surg Edinb. 1995;40:292-294.

3. 3.Kuroi K, Shimozuma K, Taguchi T, Imai H, Yamashiro H, Ohsumi S, Saito S: Pathophysiology of seroma in breast cancer. Breast Cancer.2005; 12:288-293.

4. 4. Aitken DR, Minton JP: Complications associated with mastectomy. Surg Clin North Am.1983; 63:13311352.

5. 5. Barton A, Blitz M, Callahan D, et al. Early removal of postmastectomy drains is not beneficial: results from a halted randomized controlled trial. Am J Surg 2006;191:652-656.

6. Porter KA et al. Electrocautery as a factor in seroma formation following mastectomy. Am J Surg. 1998; 176: $8-11$.

7. Ouldamer L, Caille A, Giraudeau B, et al. Quilting suture of mastectomy dead space compared with conventional closure with drain. Ann Surg Oncol. 2015;22:4233-40.

8. Pogson CJ, Adwani A, Ebbs SR: Seroma following breast cancer surgery. Eur J Surg Oncol.2003; 29:711-717.

9. Matsui Y, Yanagida H, Yoshida H, Imamura A, Kamiyama Y, Kodama H. Seroma with fibrous capsule formation requiring a surgical resection after a modified radical mastectomy: report of a case. Surg Today. 1998;28(6):669-672.

10. Qvamme G, Axelsson CK, Lanng C, Mortensen M, Wegeberg B, Okholm M, et al. Randomized clinical trial of prevention of seroma formation after mastectomy by local methylprednisolone injection. $\mathrm{Br} \mathrm{J}$ Surg. 2015;102(10):1195-1203.

11. Almond LM, Khodaverdi L, Kumar B, Coveney EC. Flap anchoring following primary breast cancer surgery facilitates early hospital discharge and reduces costs. Breast Care (Basel) 2010;5: 97-101.

12. Ten Wolde B et al. Quilting prevents seroma formation following breast cancer surgery: closing the dead space by quilting prevents seroma following axillary lymph node dissection and mastectomy. Ann Surg Oncol.2014;21:802-807.

13. Kuroi $\mathrm{K}$ et al. Effect of mechanical closure of dead space on seromaformation after breast surgery. Breast Cancer. 2006;13(3):260-265.

14. Srivastava $\mathrm{V}$ et al. Seroma formation after breast cancer surgery: what we have learned in the last two decades. J Breast Cancer. 2012;15(4):373-380.

15. Kontos M, Kothari A, Hamed H (2008) Effect of harmonic scalpel on seroma formation following surgery for breast cancer: a prospective randomized study.J BUON 13: 223-230. 
16. Schuijtvlot M Sahu AN Cawthorn SJ (2002) A prospective audit of the use of a buttress suture to seroma formation following axillary node dissection without drains. Breast 11: 94-96.

17. M. A. Sakkary, "The value of mastectomy flap fixation in reducing fluid drainage and seroma formation in breast cancer patients," World Journal of Surgical Oncology, vol. 10, article 8,2012.

18. Khater A, Elnahas W, Roshdy S, Farouk O, Senbel A, et al. (2015) Evaluation of the Quilting Technique for Reduction of Postmastectomy Seroma: A Randomized Controlled Study. Int J Breast Cancer 2015: 287398.

19. Anjani J, Amit O, Kuber S, Achal G (2016) Factors affecting seroma formation after modified radical mastectomy in patients of carcinoma breast: A prospective study. IJSS Journal of Surgery 21-5.

20. Bemmel AJ, van de Velde CJ, Schmitz RF, Liefers GJ (2011) Prevention of seroma formation after axillary dissection in breast cancer: a systematic review.Eur J Surg Oncol 37: 829-835.

21. Faisal M, Abu-Elela S, Mostafa W, and Antar O (2016) Efficacy of axillary exclusion on seroma formation after modified radical mastectomy. World J Surg Oncol 14: 39.

22. Pogson CJ et al. Seroma following breast cancer surgery. Eur J Surg Oncol.2003;29:711-717.

23. Holcombe $\mathrm{C}$ et al. The satisfaction and savings of early discharge with drain in situ following axillary lymphadenectomy in the treatment of breast cancer. Eur J Surg Oncol. 1995;21(6):604-606.

24. Say CC, Donegan W (1974) A biostatistical evaluation of complications from mastectomy. Surg Gynecol Obstet 138: 370-376.

25. Degnim AC et al. Surgical site infection (SSI) after breast surgery: impact of 2010 CDC Reporting Guidelines. Ann Surg Oncol. 2012;19(13):4099-103. 